\title{
Looking at food in sad mood: Do attention biases lead emotional eaters into overeating after a negative mood induction?
}

Citation for published version (APA):

Werthmann, J., Renner, F., Roefs, A. J., Huibers, M. J. H., Plumanns, L., Krott, N., \& Jansen, A. T. M. (2014). Looking at food in sad mood: Do attention biases lead emotional eaters into overeating after a negative mood induction? Eating Behaviors, 15(2), 230-236. https://doi.org/10.1016/j.eatbeh.2014.02.001

Document status and date:

Published: 01/04/2014

DOI:

10.1016/j.eatbeh.2014.02.001

Document Version:

Publisher's PDF, also known as Version of record

Document license:

Taverne

Please check the document version of this publication:

- A submitted manuscript is the version of the article upon submission and before peer-review. There can be important differences between the submitted version and the official published version of record.

People interested in the research are advised to contact the author for the final version of the publication, or visit the DOI to the publisher's website.

- The final author version and the galley proof are versions of the publication after peer review.

- The final published version features the final layout of the paper including the volume, issue and page numbers.

Link to publication

\footnotetext{
General rights rights.

- You may freely distribute the URL identifying the publication in the public portal. please follow below link for the End User Agreement:

www.umlib.nl/taverne-license

Take down policy

If you believe that this document breaches copyright please contact us at:

repository@maastrichtuniversity.nl

providing details and we will investigate your claim.
}

Copyright and moral rights for the publications made accessible in the public portal are retained by the authors and/or other copyright owners and it is a condition of accessing publications that users recognise and abide by the legal requirements associated with these

- Users may download and print one copy of any publication from the public portal for the purpose of private study or research.

- You may not further distribute the material or use it for any profit-making activity or commercial gain

If the publication is distributed under the terms of Article $25 \mathrm{fa}$ of the Dutch Copyright Act, indicated by the "Taverne" license above, 


\title{
Looking at food in sad mood: Do attention biases lead emotional eaters into overeating after a negative mood induction?
}

\author{
Jessica Werthmann ${ }^{\text {a,* }}$, Fritz Renner ${ }^{\text {a }}$, Anne Roefs ${ }^{\text {a }}$, Marcus J.H. Huibers ${ }^{\text {b }}$, Lana Plumanns ${ }^{\text {a }}$, \\ Nora Krott ${ }^{\mathrm{a}}$, Anita Jansen ${ }^{\mathrm{a}}$ \\ ${ }^{a}$ Maastricht University, The Netherlands \\ ${ }^{\mathrm{b}}$ VU University Amsterdam, The Netherlands
}

\section{A R T I C L E I N F O}

\section{Article history:}

Received 17 July 2013

Received in revised form 21 January 2014

Accepted 3 February 2014

Available online 14 February 2014

\section{Keywords:}

Attention bias

Eye tracking

Emotional eating

Mood induction

Food intake

\begin{abstract}
A B S T R A C T
Background: Emotional eating is associated with overeating and the development of obesity. Yet, empirical evidence for individual (trait) differences in emotional eating and cognitive mechanisms that contribute to eating during sad mood remain equivocal.

Aim: The aim of this study was to test if attention bias for food moderates the effect of self-reported emotional eating during sad mood (vs neutral mood) on actual food intake. It was expected that emotional eating is predictive of elevated attention for food and higher food intake after an experimentally induced sad mood and that attentional maintenance on food predicts food intake during a sad versus a neutral mood.

Method: Participants $(\mathrm{N}=85)$ were randomly assigned to one of the two experimental mood induction conditions (sad/neutral). Attentional biases for high caloric foods were measured by eye tracking during a visual probe task with pictorial food and neutral stimuli. Self-reported emotional eating was assessed with the Dutch Eating Behavior Questionnaire (DEBQ) and ad libitum food intake was tested by a disguised food offer.

Results: Hierarchical multivariate regression modeling showed that self-reported emotional eating did not account for changes in attention allocation for food or food intake in either condition. Yet, attention maintenance on food cues was significantly related to increased intake specifically in the neutral condition, but not in the sad mood condition.

Discussion: The current findings show that self-reported emotional eating (based on the DEBQ) might not validly predict who overeats when sad, at least not in a laboratory setting with healthy women. Results further suggest that attention maintenance on food relates to eating motivation when in a neutral affective state, and might therefore be a cognitive mechanism contributing to increased food intake in general, but maybe not during sad mood.
\end{abstract}

(c) 2014 Elsevier Ltd. All rights reserved.

\section{Introduction}

Overeating is a serious problem, as it contributes to the development of obesity (e.g., Hill, Catenacci, \& Wyatt, 2005; Lowe \& Levine, 2005). Therefore it is important to study (cognitive) mechanisms that are related to overeating (Lowe \& Levine, 2005). Different models emphasize the impact of negative emotions on excessive food intake, thereby linking emotional eating to overeating and ultimately to the risk of weight gain (e.g., Canetti, Bachar, \& Berry, 2002; Macht, 2008). Basically, it is assumed that eating in response to stress or sad mood is a maladaptive emotion regulation mechanism, which affects eating behavior and weight in general (Canetti et al., 2002; Macht, 2008). For example, emotional eaters, that is, individuals who report to be prone to overeat in response to negative emotional states, are thought to be

\footnotetext{
* Corresponding author at: Faculty of Psychology and Neuroscience, P.O. Box 616, 6200 MD Maastricht, The Netherlands. Tel.: + 31 433884558; fax: + 31433884196.

E-mail address: Jessica.Werthmann@maastrichtuniversity.nl (J. Werthmann).
}

less successful in dieting and are therefore considered to be at higher risk for developing obesity (van Strien, 2005). Yet, experimental research findings remain inconsistent with respect to the influence of negative mood on eating behavior in self-reported emotional eaters, as assessed with a standard self-report measure for emotional eating, the Dutch Eating Behavior Questionnaire (DEBQ, van Strien, Frijters, Bergers, \& Defares, 1986). Even basic assumptions, for example that self-reported emotional eating is associated with actual overeating during sad mood (thus with the very behavior that this construct is based upon) could not reliably be demonstrated. Whereas some experimental studies found that food intake after a negative mood induction increased in participants with high disinhibition tendencies and/or high self-reported emotional eating (Loxton, Dawe, \& Cahill, 2011; Yeomans \& Coughlan, 2009), others did not find an influence of emotional eating traits on food intake during distress in the lab (e.g., Evers, de Ridder \& Adriaanse, 2009; Evers, Marijn Stok, \& de Ridder, 2010; Wallis \& Hetherington, 2004, 2009, study 2). Similarly, Bongers, Jansen, Havermans, Roefs, \& Nederkoorn (2013) reported that 
emotional eating (measured with the DEBQ) was significantly related to higher intake after a positive, but not after a negative mood induction. In contrast, van Strien et al. (2013) found increased intake in high emotional eaters compared to low emotional eaters after negative and positive mood inductions. Moreover, also findings from "outside the lab", for example based on food diaries, failed to find a consistent link of self-reported emotional eating and food intake during distress in real-life settings (Adriaanse, de Ridder, \& Evers, 2011; Ayres, Prestwich, Conner, \& Smith, 2011; Conner, Fitter, \& Fletcher, 1999; Wallis \& Hetherington, 2009, study 1).

A goal of the current study was to study if self-reported emotional eating is related to elevated attention bias for food and actual food intake during sad mood (vs neutral mood). Research in addiction and eating context has already shown that elevated attention processing of desired cues (i.e., attention bias) is related to craving and consumption (Field, Munafó, \& Franken, 2009; Franken, 2003; Nijs, Franken, \& Muris, 2009). Correspondingly, several studies have shown that elevated attentional biases for high-calorie foods are related to a higher reward drive, hunger, (chronic) craving, overweight and obesity (Castellanos et al., 2009; Mogg, Bradley, Hyare, \& Lee, 1998; Tapper, Pothos, \& Lawrence, 2010; Werthmann, Roefs, Nederkoorn, \& Jansen, 2013; Werthmann et al., 2011). Thus, attention bias might be a cognitive mechanism that indicates food-related motivation and contributes to food intake. Therefore, we aimed to test if self-reported emotional eating is related to elevated attention bias for food during sad mood. Attention bias for food might be a more sensitive measure to capture food-related motivation in the laboratory, in contrast to actual food intake. Moreover, attention bias for food could also be a moderator of food intake in emotional eaters after a negative mood induction. In addition, it was examined if prolonged attention for food relates to increases in food calorie intake and if this relation is affected by mood. Particularly the attention maintenance component has been associated with motivational top-down processing and might therefore be a good indicator for eating motivation (LaBerge, 2002). Specifically, previous research examining the link of attention for appetitive cues and appetitive behavior indicated that particularly attentional maintenance on appetitive cues was associated with differences in motivation for the appetitive cue (Brignell, Griffiths, Bradley, \& Mogg, 2009; Field, Mogg, Zetteler, \& Bradley, 2004; Field et al., 2009; Werthmann, Field, Roefs, Nederkoorn, \& Jansen, 2013). Thus, to further test the importance of attention bias for emotional eating, we also aimed to explore if attentional maintenance is a better predictor of overeating during sad mood than self-reported emotional eating.

In sum, measuring attention bias for food during sad mood could serve two purposes: attentional biases for food during sad mood might be less controllable than actual eating behavior during a taste test, and might therefore offer a more sensitive, less obtrusive measure of increased eating motivation during sad mood than actual food intake in the lab for emotional eaters. In addition, assessing attentional biases for food during sad mood could provide us with more knowledge on the cognitive working mechanisms that lead to increased food intake during sad mood.

Research that examined if attention for food is related to selfreported emotional eating is sparse. Hepworth, Mogg, Brignell, and Bradley (2010) observed that during a sad mood induction a response-latency based measure of attention bias for food and selfreported appetite increased. Moreover, this bias correlated positively with emotional eating and the DEBQ score overall, however in a regression analysis the interaction term of emotional eating and experimental mood induction was not predictive for attention. Yet, direct food intake was not assessed in this study and attention biases for food were measured indirectly through reaction times. Thus, this previous result questions the link of emotional eating, attention bias for food and food intake, yet experimental evidence for this relation is still lacking and leaves therefore the exploration of cognitive mechanisms contributing to overeating in emotional eaters during sad mood unresolved.
With regard to the measurement of attention bias we extended this previous finding by employing eye tracking, which has been found to be the most sensitive and direct way to test individual differences in attention allocation in the domain of addiction (Field et al., 2009). Moreover, we made use of pictures instead of words as stimuli during the visual probe task, because it has been argued that pictures are more ecologically valid for the assessment of visual attention for appetitive cues (e.g., Brignell et al., 2009; Hepworth et al., 2010). Thus, this is, to our knowledge, the first study to test the impact of mood on attentional biases experimentally by using eye tracking as a novel and dynamic measure of visual attention allocation for pictorial food stimuli.

To summarize, the aims of this study were twofold: first, it was tested if self-reported emotional eating is related to increased attention bias for food and higher food intake in a negative affective state versus in a neutral affective state. An interaction effect of emotional eating and induced mood on attentional biases and food intake was predicted. Second, we aimed to explore if maintained attention for food would be a better predictor of food intake in a negative affective state than selfreported emotional eating.

\section{Method}

\subsection{Participants}

Participants $(\mathrm{N}=85)$ were recruited through flyers, Facebook, and via e-mail. Only female students were eligible for participation, because emotional eating has been considered mainly prominent in women (van Strien et al., 1986). Participants were randomly assigned to either the negative mood or the neutral mood condition.

\subsection{Materials and procedure}

\subsubsection{Mood induction}

A combination of music and autobiographical recall was used to induce a negative or a neutral mood, because similar mood inductions have been successfully used in previous research (Jansen et al., 2008; Martin, 1990). In the negative mood condition, participants listened to 'Adagio for Strings' by Samuel Barber for 8 min while writing about a recent negative experience, whereas participants in the neutral mood condition listened to a neutral piece of music 'Dancing with the Sun' by Celia Felix (2010) and wrote about a recent study course. A mood booster was introduced after the first half of the attention paradigm to ensure that mood levels remained negative/neutral during the testing procedure. During the booster, participants again listened to the respective music piece for $1 \mathrm{~min}$ and had to re-read their writings. Participants listened to the music pieces on headphones.

\subsubsection{Visual probe paradigm}

To assess attentional biases for food stimuli in contrast to neutral stimuli, eye movements and manual response latencies were recorded during a visual probe task. In this task two pictorial stimuli appear simultaneously on the left and right sides of a computer screen, followed by a probe (in this case a small star) that replaces one of the stimuli. Participants are instructed to respond as quickly as possible to the location of the star by pressing a corresponding key on the key board. The logic of this task presumes that the attention of the participant is automatically drawn towards the personally more relevant stimulus, and therefore leads to faster responding to the star if the star replaces the image that draws the attention. Besides the assessment of response latencies to the probe location, attention processes were measured by the recording of eye movements that occur during the stimuli presentation. The same paradigm was already used in previous research (see Werthmann et al., 2011).

2.2.2.1. Overview. Each trial started with a fixation cross that disappeared directly after participants fixated on it, which was followed 
by the stimulus pair for $2000 \mathrm{~ms}$. Then the probe appeared until participants made a manual response indicating the position of the probe.

The task consisted of 120 trials in total, which were split into two blocks of 60 trials each, during which a mood booster was introduced. In total, twenty critical stimulus pairs were presented four times, resulting in 80 critical trials. Additionally, ten non-relevant stimulus pairs were presented four times, resulting in 40 filler trials.

2.2.2.2. Stimuli. In critical trials, a photograph of a palatable high-caloric food stimulus was paired with a photograph of a non-food stimulus (music instrument). In filler trials, photographs of traffic objects were paired with photographs of office objects. All stimuli were digital photographs matched in color, complexity and brightness. Food stimuli and non-food stimuli were equally distributed over the right and left sides of the computer screen. The probe replaced equally often food and neutral stimuli and was equally distributed on the right and left screen locations. The same stimulus-set was previously used by Werthmann et al. (2011).

\subsubsection{Eye movements}

Eye movements were recorded by a desktop mounted EyeLink 1000 system (SR Research Ltd., Mississauga, Ontario, Canada). A 9-point calibration with subsequent validation procedure was conducted prior to the visual probe paradigm. To assess attention allocation processes, participants' gaze fixations during stimuli presentations were studied. Gaze fixations were defined as any period that was not a blink or saccade and lasted at least $100 \mathrm{~ms}$ (Eyelink Dataviewer User's Manual, 2002-2008, SR Research Ltd.). Eye movements that occurred before the presentation of an image pair were excluded, because these movements could represent anticipatory fixations. For analysis purposes, the computer screen was, invisible for participants, divided into three areas of interest: the mid-section, indicating the location of the fixation cross, and the left and right sections, representing the locations of the picture stimuli. Only eye movements in critical trials directed either to the left or the right section of the screen were extracted for further analyses. Eye movements in filler trials and gaze fixations in the mid area were excluded from further analyses. Eye movements were extracted using Data Viewer (SR Research Ltd., Mississauga, Ontario, Canada).

\subsubsection{Visual attentional biases}

On the basis of eye movement recordings, three visual attentional bias scores were calculated: (i) gaze direction bias which is defined as the proportion of trials on which the first fixation was directed to a food stimulus versus a non-food stimulus (a score above 50\% indicates a higher proportion of first fixations on food); (ii) initial gaze duration bias, which is a measure for early attention maintenance, computed as the difference between food and neutral stimuli in the average duration of first fixations towards the initially fixated picture before the gaze was shifted away (a positive score indicates longer initial gaze on food than on non-food stimuli), and (iii) gaze dwell time bias, which is computed as the difference between average total dwell time on food and nonfood stimuli (a positive score indicates longer dwell time on food stimuli than on non-food stimuli). For comparable measures, see for example Castellanos et al. (2009), Mogg, Bradley, Field, \& De Houwer (2003), Werthmann et al. (2011).

\subsubsection{Response latency attentional bias}

Participants' manual response latencies when reacting to the probe location were used to calculate a response latency bias. Following previous research (e.g., Castellanos et al., 2009; Mogg et al., 1998) response latencies that were faster than $200 \mathrm{~ms}$, slower than 2000, and then if they deviated more than 3 SDs from each participant's mean were excluded from further analyses. Bias scores were then calculated by subtracting the mean response latency on congruent trials (i.e., when the probe replaced a food image) from the mean response latency on incongruent trials (i.e., when the probe appeared in the same location as the preceding neutral image). A positive bias score is indicative for an attentional bias towards food stimuli, whereas a negative bias score can be interpreted as attentional avoidance, that is an attentional bias away from food stimuli.

\subsubsection{Food intake}

Food intake of participants was measured by a disguised ad libitum food offer. The experimenter disguised this measurement of food intake by telling the participant that she had to wait until the effect of the prior experimental manipulation (mood induction) wears off. The participant was further told that she should make herself comfortable, read a magazine and enjoy the offered food, if she wants to, and wait for about $10 \mathrm{~min}$, after which the experimenter would come back and the rest of the experiment would continue. Both healthy (grapes and cucumber) and unhealthy (chocolate and chips) food items were offered. The bowls with food were placed on a table with magazines (about living decoration and traveling). The food bowls were weighted before and after the waiting time. The difference in weight indicated the amount of food consumption in grams and calorie intake was calculated subsequently. None of the participants who completed a subsequent awareness check ${ }^{1}$ were suspicious of this measure of food intake.

\subsubsection{Questionnaires}

2.2.7.1. Hunger, craving and mood. Throughout the experimental procedure visual analog scales (VAS) were used to assess mood state, state craving, and hunger at five different time points (baseline (VAS1), post mood induction (VAS2), post mood booster (VAS3), post visual probe task (VAS4), post taste test (VAS5)). Participants had to indicate their mood on three VAS scales (asking for positive/negative affect, depressiveness/cheerfulness, and happiness/sadness), their feelings of hunger on two questions (asking for fullness and hunger) and their state craving on one VAS scale. All VAS scales were $100 \mathrm{~mm}$ horizontal lines running from 0 to 100, where the opposing feelings (e.g., positive affect versus negative affect) were positioned. Higher scores indicated more positive mood/more hunger/more craving, lower scores denoted a more negative mood state/less hunger/less craving. For analysis purposes average mood ratings for each VAS scale were calculated by taking the mean rating of the three mood questions per time point. Similarly, one hunger score per time point was calculated by averaging ratings of the two VAS scales asking for feelings of hunger per time point. In addition, one open question asking participants to estimate the time passed since their last meal was included in the first assessment of mood, hunger and craving, as an additional check for satiety.

\subsubsection{Dutch Eating Behavior Questionnaire (DEBQ). The DEBQ (van} Strien et al., 1986) measures eating behavior characteristics on three subscales, assessing emotional eating (13 items), external eating (10 items) and restrained eating (10 items). Items are scored on a fivepoint Likert scale ranging from 0 (never) to 5 (very often) and higher scores indicate increased emotional eating, increased external eating and more restrained eating.

\subsubsection{Procedure}

All participants were tested individually by two experimenters. One experimenter conducted the first part of the procedure including the assessment of attention bias for food, then the other experimenter conducted the rest of the procedure. Upon arrival, the participant signed the informed consent and filled in the baseline measure of mood state, hunger and craving (VAS1). Then, the negative or the neutral mood induction followed, depending on whether the participant has been randomly assigned to the experimental or the control condition and

\footnotetext{
${ }^{1}$ Awareness checks were available for 64 participants.
} 
Main sample characteristics at baseline for participants in the neutral and negative experimental condition, respectively.

\begin{tabular}{|c|c|c|c|c|c|c|}
\hline & \multicolumn{2}{|c|}{ Neutral condition $(n=43)$} & \multicolumn{2}{|c|}{ Negative condition $(\mathrm{n}=42)$} & \multirow[b]{2}{*}{$t(83)$} & \multirow[b]{2}{*}{$p$} \\
\hline & M & SD & M & SD & & \\
\hline Mood at baseline & 73.80 & 12.25 & 75.97 & 11.54 & 0.84 & .40 \\
\hline Hunger at baseline & 41.93 & 19.90 & 41.45 & 16.58 & 0.12 & .91 \\
\hline Craving at baseline & 38.49 & 25.44 & 36.00 & 21.30 & 0.49 & .63 \\
\hline Time since last meal (in min) ${ }^{\mathrm{a}}$ & 103.64 & 64.00 & 68.22 & 57.26 & 2.66 & .01 \\
\hline RS score & 11.21 & 4.77 & 9.98 & 4.42 & 1.24 & .22 \\
\hline Emotional eating (DEBQ) & 2.70 & 0.66 & 2.58 & 0.68 & 0.83 & .41 \\
\hline External eating (DEBQ) & 3.47 & 0.53 & 3.30 & 0.44 & 1.52 & .13 \\
\hline Restrained eating (DEBQ) & 2.70 & 0.77 & 2.57 & 0.79 & 0.82 & .42 \\
\hline Reward drive (BAS) & 11.70 & 1.79 & 11.26 & 1.81 & 1.12 & .27 \\
\hline Fun seeking (BAS) & 11.93 & 1.84 & 11.81 & 1.60 & 0.32 & .75 \\
\hline Reward response (BAS) & 17.70 & 1.87 & 17.43 & 1.88 & 0.66 & .51 \\
\hline BIS & 21.98 & 2.98 & 21.62 & 3.57 & 0.50 & .62 \\
\hline BMI & 22.13 & 2.71 & 21.63 & 2.24 & 0.92 & .36 \\
\hline Age & 20.81 & 2.06 & 20.48 & 1.99 & 0.77 & .45 \\
\hline
\end{tabular}

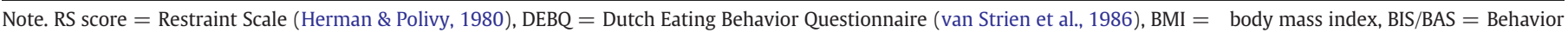
Activation/Behavior Inhibition Scales (Carver \& White, 1994).

a Two participants did not fill in this question and were counted as missing for this analysis. The power of the $t$-test is based on 81 degrees of freedom.

the participant subsequently filled in VAS2. Afterwards she participated in the first half of the visual probe task, and then the mood induction was briefly repeated in a one-minute mood booster during a break between two blocks of the visual probe paradigm. Before starting the second block of the visual probe task, she filled in VAS3. After completion of the visual probe task, the participant filled in VAS4. Then, a cover story was used to disguise the direct assessment of food intake, which was measured after the participant was left alone with four kinds of food for $10 \mathrm{~min}$. Upon return of the experimenter, the participant filled in VAS5 and then filled in the additional questionnaires (restraint scale by Herman \& Polivy, 1980, DEBQ behavior approach/ behavior inhibition scales (BIS/BAS) by Carver \& White, 1994). A brief awareness check was conducted afterwards. At the end of the experiment, weight and height were measured, the participant was thanked for her participation and was compensated with either a course credit or $€ 7.50$.

\subsection{Analyses}

Independent sample $t$-tests were conducted to test whether the experimental and the control group differed on hunger, craving, baseline affective state, restraint scores (as assessed with the restraint scale and the DEBQ), external eating scores, emotional eating scores (as assessed with the DEBQ), impulsivity (as assessed with the BIS/BAS scales), age and body mass index (BMI) as randomization check. To check whether the mood induction was successful a repeated measures analyses of variance (ANOVA) with average mood ratings from the VAS scales on 5 time points as within-subjects variable and experimental condition (neutral, negative) as between-subjects variable was tested. Hierarchical multivariate linear regression analyses were conducted to test if self-reported emotional eating is related to attention to food and food intake in a negative affective state versus a neutral state (hypothesis 1). For this aim, five linear hierarchical multivariate regression models (for direction bias, initial gaze duration bias, dwell time bias, response latency bias and for food intake in calories) were conducted to test the effects of emotional eating and affective state on attention and on (over)eating. In the first step emotional eating (centered) and the mood condition (as dummy variable) were entered. In the second step the emotional eating $\times$ mood condition interaction was entered. In line with the hypothesis a significant interaction effect of emotional eating and mood condition on increased attention and food intake was expected.

To test our second research question, if maintained attention (i.e., dwell time bias) would be a better predictor of food intake in a negative affective state than self-reported emotional eating, another hierarchical multivariate linear regression analysis was conducted. In the first step, mood condition (as dummy variable), emotional eating (centered variable) and dwell time attentional bias scores (centered variable) were entered. In the second step, the interactions of emotional eating $\times$ mood condition and of dwell time attentional bias scores $\times$ mood condition were entered.

\section{Results}

\subsection{Group characteristics}

Independent sample $t$-tests confirmed that there were no significant differences between participants in the negative mood and the neutral mood condition with regard to self-reported hunger, craving, BMI, age, restraint scores, external eating scores, emotional eating scores, impulsivity, and affective state at baseline (all $t s<1.24$ and all $p s>.22$ ). Participants in the neutral mood condition, however, reported a significant longer time since their last meal than participants in the negative mood condition. Yet, self-reported hunger scores did not seem to be influenced by this difference. Thus, participants in both conditions arrived in similar mood and hunger states for the experiment. See Table 1 for all participant characteristics.

\subsection{Mood induction}

Results from the repeated measures ANOVA testing whether the mood manipulation successfully induced a mood decrease in the negative mood condition showed a significant mood condition $\times$ time interaction, $F(2.74,82)^{2}=38.79, p<.001$, suggesting that mood indeed decreased significantly in the negative mood condition but remained unaltered in the neutral mood condition. Independent-sample $t$-tests confirmed significant differences between conditions at time 2 , thus after the induction, $\left(t(82)^{3}=6.19, p<.001\right)$, time 3 , that is after the mood booster, $(t(83)=5.91, p<.001)$, and time 4 , prior to the taste test, $(t(83)=3.48, p<.01)$. At time 5 (at the end of the experiment; that is after a 10 min break) no significant difference between conditions was detected $(t(83)=1.23, p=.22)$. See Fig. 1 for changes in mood per condition for all time points.

\footnotetext{
2 Mauchly's test indicated that the assumption of sphericity had been violated, therefore degrees of freedom were corrected using Greenhouse-Geisser estimate of sphericity.

${ }^{3}$ One participant did not fill in the VAS at time 2.
} 


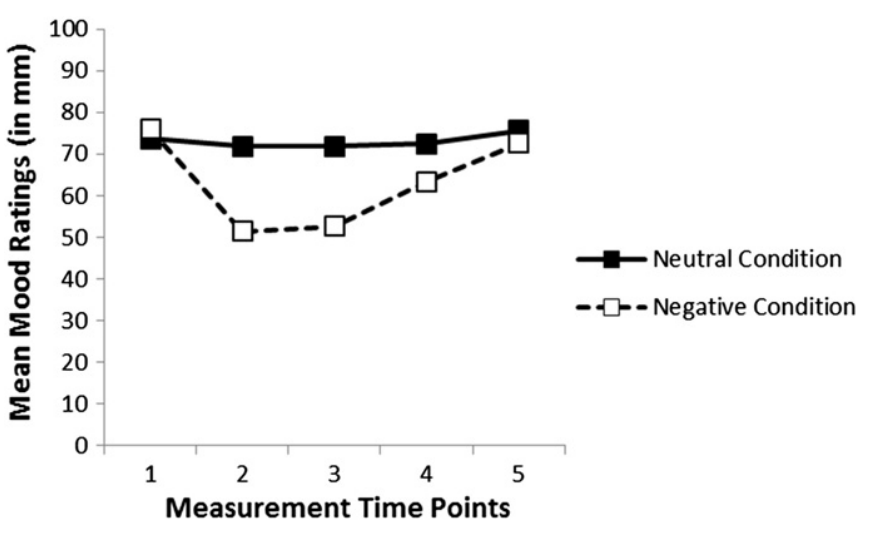

Fig. 1. Mean mood ratings (lower values indicate stronger negative affect) per condition (negative versus neutral condition) on time 1 (at baseline), time 2 (after the mood induction), time 3 (mood booster during visual probe task), time 4 (prior to taste test) and time 5 (after food intake measure).

\subsection{Main analyses}

\subsubsection{Effect of condition and emotional eating on attention for food}

Results from the regression analyses on the influence of emotional eating and affective state on attention for food revealed no significant main effect of emotional eating, all $\beta \mathrm{s}<.17$, ts $<1.52$, $p \mathrm{~s}>.13$. There was a significant main effect of the mood condition on the direction of attention, $\beta=.22, t=2.02, p=.047$, indicating that participants in the neutral mood condition had a significantly higher initial orientation towards food $(M=55.38, \mathrm{SD}=7.53)$ than participants in the negative mood condition $(M=52.74, \mathrm{SD}=4.56)$. No significant emotional eating $\times$ mood condition interaction effects were observed on any attentional bias scores, all $\beta \mathrm{s}<.09$, all $t \mathrm{~s}<0.58$, all $p s>.56$. The inclusion of the interaction term of emotional eating $\times$ mood condition did not add to the explained variance of the model, all $\mathrm{Rs}^{2}<.06$, all $\Delta \mathrm{R}^{2} \mathrm{~s}$ $<.004$, all $F s(3,81)<1.68$ all $p s>.56$. The results from these regression analyses thus indicate that self-reported emotional eating was not associated with attention bias for food during negative mood.

\subsubsection{Effect of condition and emotional eating on food intake}

No significant main effect of emotional eating, $\beta=.11, t=0.95, p=$ .34 and no significant emotional eating $\times$ mood condition interaction effect, $\beta=.12, t=0.74, p=.46$, were observed for food intake. ${ }^{4}$ The inclusion of the emotional eating $\times$ mood condition interaction did not add to the explained variance of the model, $R^{2}=.02, \Delta R=.004$, $F(3,81)=0.51, p=.68$. This means that self-reported emotional eating was not associated with food intake during negative affective state.

\subsubsection{Association of maintained attention on food intake in a negative $\operatorname{mood}$}

As no significant relation between emotional eating and food intake was found in the previous analysis, we decided to conduct the final regression analysis only on the effect of maintained attention and mood condition on food intake. The results of this regression analysis indicated a significant main effect of attentional maintenance (i.e., dwell time bias scores) on food intake in step 1: longer dwell time scores were associated with more food intake, $\beta=.35, t=3.35$, $p<.01$. More importantly the interaction term of dwell time attentional bias scores $\times$ mood condition was significant in step two of the analysis, $\beta=-.32, t=2.38, p<.05$, see Table 2 for all respective coefficient values.

To further explore the direction of this significant interaction, simple slope testing was conducted. Simple slopes testing the effect of dwell

\footnotetext{
${ }^{4}$ As food intake was positively skewed, sensitivity analyses with log-transformed food intake were conducted. The results remained the same, and the results here reported are based on the original values of food intake (in calories).
}

Table 2

Summary of linear hierarchical multivariate regression analysis of variables predicting food intake (in cal).

\begin{tabular}{lllrrr}
\hline Step & Predictor & B (SE) & \multicolumn{1}{l}{$\beta$} & \multicolumn{1}{l}{$t$} & \multicolumn{1}{l}{$p$} \\
\hline \multirow{2}{*}{ Step 1} & Mood condition & $-1.63(24.45)$ & -.007 & -0.07 & .947 \\
& Dwell time & $0.20(0.06)$ & .347 & 3.35 & .001 \\
Step 2 & Mood condition $\times$ dwell time & $-0.29(0.12)$ & -.319 & 2.38 & .020 \\
\hline Note. $R^{2}=$ & .12 for step $1 p=0.005 ; R^{2}=$ & $.18, \Delta \mathrm{R}^{2}=.06$ for step $2, p=0.02$.
\end{tabular}

time attentional bias scores per condition showed that dwell time on food affected food intake significantly in the neutral mood condition; $\beta=.56, t=4.16, p<.001$, longer attentional maintenance was associated with more food consumption, yet, in the negative mood condition dwell time for food did not affect food intake; $\beta=-.35, t=$ $0.47, p=.642$ (see Fig. 2). Simple slope testing for the effect of high $(+1 \mathrm{SD})$ or low $(-1 \mathrm{SD})$ dwell time for food on subsequent food intake showed a trend for differences between conditions: participants with longer dwell time for food ( $+1 \mathrm{SD}$ ) ate trend-significantly more food in the neutral condition than in the negative condition; $\beta=-.25, t=$ $-1.75, p=.084$. Participants with shorter dwell time for food $(-1 \mathrm{SD})$ did not differ in their food intake between conditions; $\beta=$ $.24, t=-1.64, p=.11$. These results mean that longer attentional maintenance on food stimuli was significantly associated with higher food intake in the neutral but not in the negative mood condition, whereas self-reported emotional eating was not predictive of food intake, in neither condition.

\section{Discussion}

The main aim of this study was to test experimentally if selfreported emotional eating is related to increased attention bias for food and increased food intake after a sad mood induction. A second aim was to test whether the attention maintenance bias component, that is dwell time on food stimuli, predicts food intake during sad mood to a larger extent than self-reported emotional eating (based on the DEBQ).

Our results indicate that self-reported emotional eating, at least when assessed by the DEBQ did neither account for attentional biases for food nor for actual food intake during sad mood, in the current sample. With regard to food intake, our results dovetail with previous findings that also did not find elevated food intake in response to negative feelings in self-identified emotional eaters according to the DEBQ (e.g., Adriaanse et al., 2011; Bongers et al., 2013; Bongers, Jansen, Houben, \& Roefs; Conner et al., 1999; Evers et al., 2009; Evers, de Ridder, \& Adriaanse, 2010). Other authors have already offered an

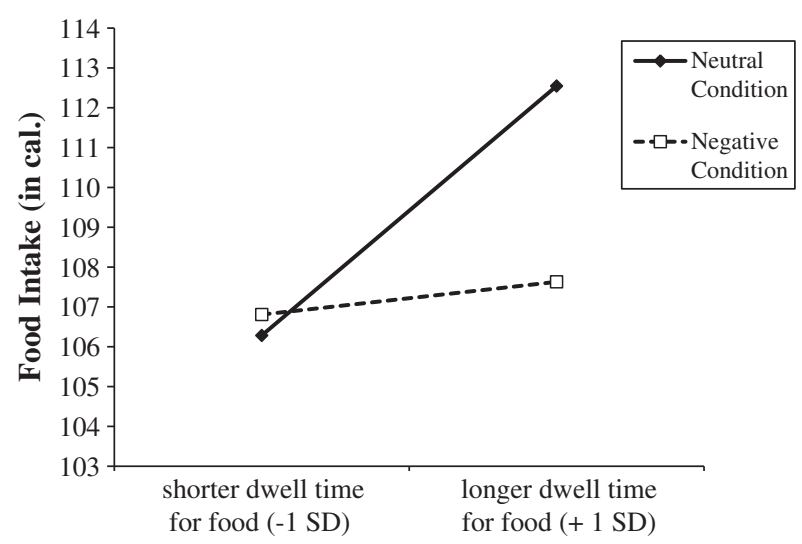

Fig. 2. Food intake (in cal.) as a function of dwell time attentional bias scores (1 SD below and $1 \mathrm{SD}$ above the mean dwell time attentional bias score, respectively) and mood condition (negative and neutral mood induction). 
explanation for this observation: for example Adriaanse et al. (2011) suggested that self-assessment of emotional eating might be difficult (and therefore invalid) because of a possible recall bias as emotional states can affect recall immensely.

With regard to attention bias for food, the current results demonstrate that self-reported emotional eating was not related to increased attention for food during negative mood in this student sample. The current study is the first evidence, to our knowledge, that tested this relation directly by means of eye tracking. In line with our finding, one previous study using a response latency-based measure for attentional processes did also not find an association of emotional eating and a response latency-based attentional bias for food, thereby also suggesting that self-reported emotional eating is not related to increased attention bias for food during sad mood (Hepworth et al., 2010). Altogether, the current results contribute to further evidence that self-reports of emotional eating, at least as measured by the DEBQ do not accurately predict increased attention bias for food or increased food intake when feeling sad (Adriaanse et al., 2011; Bongers et al., 2013; Bongers et al.; Evers et al., 2009; Evers, de Ridder, et al., 2010; Hepworth et al., 2010).

Whereas our results concerning the link of emotional eating and attention bias for food and food intake are similar to an earlier study, our findings differ from the results by Hepworth et al. (2010) with regard to changes in attention due to an experimental mood induction. Hepworth et al. (2010) observed a main effect of their mood induction on their measure of attention bias for food, in that a negative mood increased attention bias for food cues, whereas the results from our study showed that the negative mood induction decreased initial orientation towards food. These differences are not likely due to different mood induction procedures, because fairly similar experimental procedures were applied in both studies. However, the divergence of findings might be explained by a different choice in the assessment of attention bias for food: Hepworth and her colleagues used a response latencybased, thus indirect, measure of visual attention whereas in the current study a more direct assessment of visual attention, namely eyemovement recordings were included. In addition, Hepworth et al. collapsed the two attentional components (an early, assessed at $500 \mathrm{~ms}$, and a later component, assessed at $2000 \mathrm{~ms}$ ) when reporting their main effect of mood induction on attention measures, whereas we analyzed the data of the four attention components assessed in our study separately.

Even though an interpretation remains speculative at this point and needs further testing, our finding that negative affect decreases an orientation bias for food might indicate that negative mood in general decreases the attractiveness and/or rewarding value of otherwise highly salient and rewarding stimuli. This suggestion fits with recent evidence showing that sad mood decreases reward sensitivity (Foti \& Hajcak, 2010; Hervas \& Vazquez, 2013). Another explanation for the finding that initial orientation bias to food cues was higher in the neutral condition, than in the negative mood condition, is that more time had elapsed since the last meal for participants in the neutral condition. However, this explanation is unlikely because the mean hunger ratings did not differ between the two groups ( $41 \mathrm{~mm}$ on a $100 \mathrm{~mm}$ scale ranging from not hungry (0) to very hungry (100) for both groups).

With regard to our second hypothesis, our results demonstrated that longer dwell time on food stimuli was associated with increased food intake, at least in the neutral condition, within the current sample of female students. This finding suggests that attentional maintenance on food is related to subsequent food intake, because individuals with longer attention focus on food were inclined to consume more food. Apparently maintaining one's gaze on food contributes to food intake, in a neutral affective state. In this respect, this finding corroborates with previous suggestions that attention focus on food is related to food consumption (Hofmann \& Van Dillen, 2012; Kavanagh, Andrade, \& May, 2005; Tiggemann \& Kemps, 2005; Werthmann, Field, et al., 2013; Werthmann, Roefs, et al., 2013). Yet, against our hypothesis, during negative mood this relation could not be established.
Altogether, our current results suggest that attentional biases for food could eventually constitute a cognitive mechanism contributing to overeating, even though not during negative mood. Attention biases should therefore be assessed as an additional and informative measure next to self-reported eating motivation. Self-reported eating motivation might be inaccurate due to social desirable response tendencies. For example, it has been shown that participants who score high on a social desirability questionnaire also report lower emotional eating scores on the DEBQ (Allison \& Heshka, 1993). Assessment of eating motivation using behavioral or physiological assessments might therefore compliment self-report instruments in situations when social desirable response tendencies are likely, for example when assessing eating motivation in overweight or underweight participants. As attentional biases for food can be directly linked to food intake, another advantage of this assessment is that attention bias might provide a more automatic, thus less obtrusive measurement of eating motivation, besides measure(s) of self-report.

In terms of clinical relevance our findings highlight the impact of an obesogenic food environment on eating behavior because they provide evidence that if attention is maintained on food cues, the chance of overeating increases. Yet, this interpretation should be viewed under some limitations of our study. We have tested female college students and therefore our results are not generalizable to other populations. In this respect, it would be fruitful for future research to explore if our findings can be replicated in clinical samples, for example in eating disordered patients, obese participants or depressed patients. Moreover, we feel inclined to mention that even though our mood induction produced a significant decrease in mood, the ratings of participants in the experimental group indicate that their mood was moderately negative instead of severely negative (mean mood rating was 51.37 on a $100 \mathrm{~mm}$ scale after the negative mood induction), or simply less positive than in the control group (mean mood rating was 71.89 after the neutral mood induction). Therefore, future research should determine whether negative affect and sad mood, in contrast to moderately negative mood have more pronounced effects on attention bias for food and food intake. Otherwise, it would also be interesting to explore whether positive mood affects attention bias for food and food intake.

Keeping these limitations in mind, the current research showed that individuals' attention focus for food is related to subsequent food intake and thereby suggesting that attention bias for food could be a cognitive mechanism contributing to overeating. However, during negative mood attention bias for food did not affect increased food intake. The extent to which this relationship is affected by more extreme mood changes remains to be explored.

\section{Role of funding source}

Jessica Werthmann is funded by a PhD fellowship from Maastricht University. The funding source had no role in the study design, the collection, analysis or interpretation of the data.

\section{Contributors}

All authors contributed to the design of the study and writing of the manuscript. Lana Plumanns and Nora Krott collected the data. Jessica Werthmann and Fritz Renner conducted the data analyses.

\section{Conflict of interest}

The authors declare that they have no conflict of interest.

\section{References}

Adriaanse, M.A., de Ridder, D. T. D., \& Evers, C. (2011). Emotional eating: Eating when emotional or emotional about eating? Psychology E' Health, 26(1), 23-39. http://dx.doi.org/10.1080/08870440903207627 (Article).

Allison, D. B., \& Heshka, S. (1993). Social desirability and response bias in self-reports of “emotional eating". Eating Disorders, 1(1), 31-38. http://dx.doi.org/10.1080/ 10640269308248264

Ayres, K., Prestwich, A., Conner, M., \& Smith, P. (2011). Emotional eating moderates the relationship between implicit measures of attitudes and chocolate consumption. European Journal of Personality, 25(5), 317-325. http://dx.doi.org/10.1002/per.793. 
Bongers, P., Jansen, A., Havermans, R., Roefs, A., \& Nederkoorn, C. (2013). Happy eating: The underestimated role of overeating in a positive mood. Appetite, 67, 74-80.

Bongers, P., Jansen, A., Houben, K., \& Roefs, A. (2013). Happy eating: The single target implicit association test predicts overeating after positive emotions. Eating Behaviors, 14(3), 348-355. http://dx.doi.org/10.1016/j.eatbeh.2013.06.007.

Brignell, C., Griffiths, T., Bradley, B. P., \& Mogg, K. (2009). Attentional and approach biases for pictorial food cues. Influence of external eating. Appetite, 52(2), 299-306. http://dx.doi.org/10.1016/j.appet.2008.10.007.

Canetti, L., Bachar, E., \& Berry, E. M. (2002). Food and emotion. Behavioural Processes, $60(2), 157-164$.

Castellanos, E. H., Charboneau, E., Dietrich, M. S., Park, S., Bradley, B. P., Mogg, K., et al. (2009). Obese adults have visual attention bias for food cue images: Evidence for altered reward system function. International Journal of Obesity, 33(9), 1063-1073. http://dx.doi.org/10.1038/ijo.2009.138 (Article).

Carver, C. S., \& White, T. L. (1994). Behavioral Inhibition, Behavioral Activation, and Affective Responses to Impending Reward and Punishment: The BIS/BAS Scales. [Article]. Journal of Personality \& Social Psychology, 67(2), 319-333.

Conner, M., Fitter, M., \& Fletcher, W. (1999). Stress and snacking: A diary study of daily hassles and between-meal snacking. Psychology \& Health, 14(1), 51 (Article).

Evers, C., de Ridder, D. T. D., \& Adriaanse, M.A. (2009). Assessing yourself as an emotional eater: Mission impossible? Health Psychology: Official Journal of the Division of Health Psychology, American Psychological Association, 28(6), 717-725. http://dx.doi.org/ 10.1037/a0016700

Evers, C., de Ridder, D. T. D., \& Adriaanse, M.A. (2010). Adequately predicting emotional eating with self-reports: Not as easy as pie. Health Psychology, 29(4), 344-345. http://dx.doi.org/10.1037/a0020228.

Evers, C., Marijn Stok, F., \& de Ridder, D. T. (2010). Feeding your feelings: Emotion regulation strategies and emotional eating. Personality and Social Psychology Bulletin. 36(6), 792-804.

Felix, C. (2010). Dancing with the sun. In Cafe de Mar (Ed.), Vol. 16 (cd-compilation).

Field, M., Mogg, K., Zetteler, J., \& Bradley, B. P. (2004). Attentional biases for alcohol cues in heavy and light social drinkers: The roles of initial orienting and maintained attention. Psychopharmacology, 176(1), 88-93. http://dx.doi.org/10.1007/s00213004-1855-1.

Field, M., Munafó, M. R., \& Franken, I. H. A. (2009). A meta-analytic investigation of the relationship between attentional bias and subjective craving in substance abuse. Psychological Bulletin, 135(4), 589-607. http://dx.doi.org/10.1037/a0015843.

Foti, D., \& Hajcak, G. (2010). State sadness reduces neural sensitivity to nonrewards versus rewards. NeuroReport: For Rapid Communication of Neuroscience Research, 21(2), 143-147. http://dx.doi.org/10.1097/WNR.0b013e3283356448.

Franken, I. H. A. (2003). Drug craving and addiction: integrating psychological and neuropsychopharmacological approaches. Progress in Neuro-Psychopharmacology $\mathcal{E}$ Biological Psychiatry, 27(4), 563-579. http://dx.doi.org/10.1016/S0278-5846(03) 00081-2.

Hepworth, R., Mogg, K., Brignell, C., \& Bradley, B. P. (2010). Negative mood increases selective attention to food cues and subjective appetite. Appetite, 54(1), 134-142. http://dx.doi.org/10.1016/j.appet.2009.09.019.

Herman, C. P., \& Polivy, J. (1980). Restrained Eating. In A. J. Stunkard (Ed.), Obesity (pp. 209-224). Philadelphia: Saunders.

Hervas, G., \& Vazquez, C. (2013). Low spirits keep rewards subdued: Decreases in sensitivity to reward and vulnerability to dysphoria. Behavior Therapy, 44(1), 62-74. http://dx.doi.org/10.1016/j.beth.2012.07.003.

Hill, J. O., Catenacci, V., \& Wyatt, H. R. (2005). Obesity: Overview of an epidemic. Psychiatric Clinics of North America, 28(1), 1-23. http://dx.doi.org/10.1016/ j.psc.2004.09.010.

Hofmann, W., \& Van Dillen, L. (2012). Desire: The new hot spot in self-control research. Current Directions in Psychological Science, 21(5), 317-322. http://dx.doi.org/ $10.1177 / 0963721412453587$.
Jansen, A., Vanreyten, A., van Balveren, T., Roefs, A., Nederkoorn, C., \& Havermans, R. (2008). Negative affect and cue-induced overeating in non-eating disordered obesity. Appetite, 51(3), 556-562.

Kavanagh, D. J., Andrade, J., \& May, J. (2005). Imaginary relish and exquisite torture: The elaborated intrusion theory of desire. Psychological Review, 112(2), 446-467.

LaBerge, D. (2002). Attentional control: Brief and prolonged. Psychological Research, 66(4), 220-233.

Lowe, M. R., \& Levine, A. S. (2005). Eating motives and the controversy over dieting: Eating less than needed versus less than wanted. Obesity Research, 13(5), 797-806. http://dx.doi.org/10.1038/oby.2005.90.

Loxton, N. J., Dawe, S., \& Cahill, A. (2011). Does negative mood drive the urge to eat? The contribution of negative mood, exposure to food cues and eating style. Appetite, 56(2), 368-374. http://dx.doi.org/10.1016/j.appet.2011.01.011.

Macht, M. (2008). How emotions affect eating: A five-way model. Appetite, 50(1), 1-11 http://dx.doi.org/10.1016/j.appet.2007.07.002.

Martin, M. (1990). On the induction of mood. Clinical Psychology Review, 10, 669-697.

Mogg, K., Bradley, B. P., Field, M., \& De Houwer, J. (2003). Eye movements to smoking-related pictures in smokers: Relationship between attentional biases and implicit and explicit measures of stimulus valence. Addiction, 98(6), 825-836.

Mogg, K., Bradley, B. P., Hyare, H., \& Lee, S. (1998). Selective attention to food-related stimuli in hunger: Are attentional biases specific to emotional and psychopathological states, or are they also found in normal drive states? Behaviour Research and Therapy, 36(2), 227-237. http://dx.doi.org/10.1016/S0005-7967(97)00062-4.

Nijs, I. M. T., Franken, I. H. A., \& Muris, P. (2009). Enhanced processing of food-related pictures in female external eaters. Appetite, 53(3), 376-383. http://dx.doi.org/ 10.1016/j.appet.2009.07.022.

Tapper, K., Pothos, E. M., \& Lawrence, A.D. (2010). Feast your eyes: Hunger and trait reward drive predict attentional bias for food cues. Emotion (Washington, D.C.), 10(6) 949-954. http://dx.doi.org/10.1037/a0020305.

Tiggemann, M., \& Kemps, E. (2005). The phenomenology of food cravings: The role of mental imagery. Appetite, 45(3), 305-313.

van Strien, T. (2005). Lijnen helpt niet bij emotionele eters. Gedrag \& Gezondheid: Tijdschrift voor Psychologie en Gezondheid, 33(4), 268-276.

van Strien, T., Cebolla, A., Etchemendy, E., Gutiérrez-Maldonado, J., Ferrer-García, M. Botella, C., et al. (2013). Emotional eating and food intake after sadness and joy. Appetite, 66, 20-25. http://dx.doi.org/10.1016/j.appet.2013.02.016.

van Strien, T., Frijters, J. E. R., Bergers, G. P. A., \& Defares, P. B. (1986). The Dutch Eating Behavior Questionnaire (DEBQ) for assessment of restrained emotional, and external eating behavior. International Journal of Eating Disorders, 5(2), 295-315. http://dx.doi.org/10.1002/1098-108X(198602)5:2<295:: AID-EAT2260050209>3.0.CO;2-T.

Wallis, D. J., \& Hetherington, M. M. (2004). Stress and eating: The effects of ego-threat and cognitive demand on food intake in restrained and emotional eaters. Appetite, 43(1), 39-46.

Wallis, D. J., \& Hetherington, M. M. (2009). Emotions and eating. Self-reported and experimentally induced changes in food intake under stress. Appetite, 52(2), 355-362. http://dx.doi.org/10.1016/j.appet.2008.11.007.

Werthmann, J., Field, M., Roefs, A., Nederkoorn, C., \& Jansen, A. (2013). Attention bias for chocolate increases chocolate consumption - An attention bias modification study Journal of Behavior Therapy and Experimental Psychiatry, 45(1), 136-143.

Werthmann, J., Roefs, A., Nederkoorn, C., \& Jansen, A. (2013). Desire lies in the eyes: Attention bias for chocolate is related to craving and self-endorsed eating permission. Appetite, 1(13), 00313-00319.

Werthmann, J., Roefs, A., Nederkoorn, C., Mogg, K., Bradley, B. P., \& Jansen, A. (2011). Can(not) take my eyes off it: Attention bias for food in overweight participants. Health Psychology, 30, 561-569. http://dx.doi.org/10.1037/a0024291.

Yeomans, M. R., \& Coughlan, E. (2009). Mood-induced eating. Interactive effects of restraint and tendency to overeat. Appetite, 52(2), 290-298. http://dx.doi.org/ 10.1016/j.appet.2008.10.006. 